\title{
Pore Pressure and Fracture Pressure Forecast in Niger Delta
}

\author{
${ }^{1}$ John Lander Ichenwo and ${ }^{2}$ Ayimora Olatunji \\ Department of Petroleum and Gas Engineering, \\ University of Port Harcourt, \\ Port Harcourt, Nigeria
}

\begin{abstract}
This study is aimed at predicting the Pore Pressure and Fracture Pressure Forecast in Niger Delta region. . It uses field data gotten from the region as case study. Two pore pressure forecast models and three fracture forecast models are explored. The pore pressure models are the resistivity model and the sonic transit tine models build uped by Ben Eaton; while the fracture pressure forecast model used are the Eaton's model, Hubbert and Willis model, and Matthew and Kelly's model. Results obtained for the pore pressure shows dependence on overburden pressure gradient and the formation depth of curiosity for both the resistivity and sonic transit model; while the results gotten for fracture pressure shows great similarity in terms of their dependence on the pore pressure, overburden pressure gradient and stress allotment. However, the Matthew and Kelly model could not be demonstrated because of the matrix stress coefficient was unavailable. This study concludes that the Eaton's model is the best model to use because of its ease of application; while it recommended that studies be conducted to build up an entirely new pore pressure and fracture pressure forecast model that will take into consideration the inherent peculiarities of the Niger Delta region.
\end{abstract}

\section{INTRODUCTION}

The basin of the Niger Delta in Nigeria is the most prolific and economic viable sedimentary basin in Nigeria with a total covering of $300,000 \mathrm{~km}$ and $10 \mathrm{~km}$ thickness of sediments by virtue of the size of petroleum accumulations, discovered and produced hydrocarbon, and spread of hydrocarbon resources.

Drilling operations whether on land, shallow offshore and in deep-water is a tremendous logistic challenge and it is expensive too. And, overpressure within the subsurface is of great concern to all operators worldwide. Penetrating unanticipated over-pressured strata or inadequate preparation can lead to serious environmental disaster and in some cases fatality. The potential impact of subsurface overpressure on the overall success or failure of a drilling campaign underscores the importance of this study in Niger Delta. And it is important, also for drilling safety, managing exploration risk (Opara and Onuoha, 2009).

\section{A Brief Geology of the Niger Delta}

As already detailed in literature, the Niger Delta Basin is made up of three main litho-stratigraphic formations which are Benin, Agbada, and Akata Formations. Few drilling efforts have penetrated the deep abnormally pressured parts of the aforementioned area with reported cases of mud losses, well kicks, stuck pipes and caving of the well bore leading to costly down time, tool losses and extra-budgetary sidetracks. Thus as the quest for deeper-lying reservoirs expand, it becomes of greater curiosity to broaden our understanding of the overpressure evolving mechanisms with a view to build up and make use of the right strategies for optimal success. Key to this is a profound understanding needed for the processes that create overpressures and best practice solutions to recognizing these processes in sedimentary basins such as Niger Delta.

\section{Overpressures in the Niger Delta}

Overpressures in the Niger Delta have involved the attention of operators and researchers quite early into the progress of oil and gas activities in the basin where the depth of infiltration of exploration wells were up till now determined more or less by the happening of first kicks in such wells. This practice seemed to be borne on the certainty that the happening of first kick should mark the beginning of overpressure hence the extinction of drilling. With precautionary expands in mud weight, target depths were often achieved with many of such wells erroneously classified as non-over pressured on the basis that no kicks were experienced. Earlier studies by Wegman (1963) relied on the kicks and reversals in log trends to build up a series of pressure graphs and rudimentary maps aimed at delineating the beginning of overpressures and their allotment in the basin based on such convictions that under compaction was the cause of the overpressures.

Most of these maps and accompanying data were however not published. These background pressure studies mapped the delta into four pressure zones. As more data became available from the drilling campaigns, it was further proved that beginning of overpressures varied widely between $4494 \mathrm{ft}(1370 \mathrm{~m})$ tvdss to $14006 \mathrm{ft}(4270 \mathrm{~m})$ tvdss with a very diffuse trend in spatial allotment thus diminishing the importance of isobar maps in pressure forecast.

Results and data offered in Anowai et al. (2003) demonstrate that the top of overpressure is relatively shallower in the Northern and Greater Ughelli Depobelts when compared with the Central Swamp Depobelt and other near-to-offshore fault-bounded mega structures. This follows from recommendations in Krusi (1990) which took a more quantitative approach by investigating he synergy between the top of overpressures with both shaliness and rate of subsidence and noted a blueprint of pressure expands where net-to-gross ratio drops below $35 \%-20 \%$ in 
proximity with discontinuous or detached reservoirs such as beach and channel sands.

Bourgoyne et al (1991) clearly summarized four mechanisms for evolving abnormal pore pressures or overpressures; these mechanisms are Compaction, Diagenesis, Differential Density and Fluid Migration.

\section{METHODOLOGY}

The method adopted is the Eaton's Model, which seeks to ascertain seismic or acoustic velocity and resistivity data. It examined the porosity vs. depth data.

Principles

The correlation of the observed parameter \& normal parameter ratio and formation pressure depends on change in overburden pressure. Eaton in 1972 established the following empirical relationship from obtained field data:

$G_{p}=G_{o b}-\left(G_{o b}-G_{p n}\right)\left(R_{s h . a} / R_{s h . n}\right)^{1.5}$ equation 1

With more experimental data and performing of his studies he published his result in 1975 as following formulas:

$$
\begin{aligned}
& G_{p}=G_{o b}-\left(G_{o b}-G_{p n}\right)\left(R_{a} / R_{n}\right)^{1.2} \ldots \\
& G_{p}=G_{o b}-\left(G_{o b}-G_{p n}\right)\left(\Delta t_{n} / \Delta t_{a}\right)^{3} . \\
& G_{p}=G_{o b}-\left(G_{o b}-G_{p n}\right)\left(d_{c . a} / d_{c . n}\right)^{1.2}
\end{aligned}
$$

Where

$$
\begin{aligned}
& \mathrm{G}_{\mathrm{p}}=\text { pore pressure gradient }(\mathrm{psi} / \mathrm{ft}) \\
& \mathrm{G}_{\mathrm{ob}}=\text { overburden gradient }(\mathrm{psi} / \mathrm{ft}) \\
& \mathrm{G}_{\mathrm{pn}}=\text { normal pore pressure gradient }(\mathrm{psi} / \mathrm{ft})
\end{aligned}
$$

$\mathrm{R}_{\mathrm{a}}, \mathrm{R}_{\mathrm{n}}=$ resistivity for actual and normal case

$\Delta \mathrm{t}_{\mathrm{a}}, \Delta \mathrm{t}_{\mathrm{n}}=$ Sonic transit time for actual and normal case $(\mu \mathrm{sec} / \mathrm{ft}$ or $\mu \mathrm{sec} / \mathrm{m})$

$\mathrm{d}_{\mathrm{c} . \mathrm{a}}, \mathrm{d}_{\mathrm{c} . \mathrm{n}}=\mathrm{dc}$-exponents for normal and actual case Respectively.

This method is empirically derived. It assumes that a normal trend can be defined and that the pore pressure at any point can be corlinked to the ratio between actual and normal indicator value.

\section{Formation Fracture Pressure Forecast}

When planning the well, both the formation pore and formation fracture pressure, for all of the formations to be penetrated must be approximated. A number of theoretical and field-build uped equations were deployed to approximate fracture gradients. Many of these are appropriate for instant application in a particular area. It required a careful approach based on density (or other) logging measurements taken after the well been drilled. The history or geological structure of the field will aid the calculation procedures for these areas, thereby utilizing leak-off tests or logging methods.

These methods are:

- Hubbert \& Willis Method

- Matthews and Kelly Method

- Ben Eaton Method

\section{Hubbert and Willis Method}

Hubbert and Willis explored the variables involved in commencing a fracture in formation. The gradient is dependent of overburden stress, formation pressure, and a synergy between the horizontal/vertical stresses. They alleged this stress relationship to be in the spectrum of $1 / 3$ to $1 / 2$ of the total overburden. Therefore fracture gradient deextinction would be as follows:

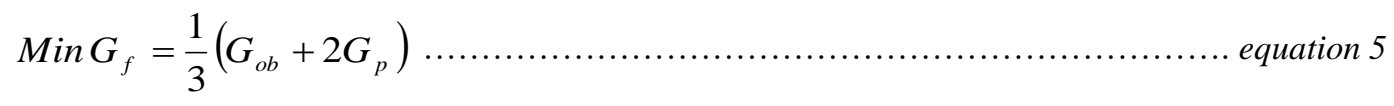

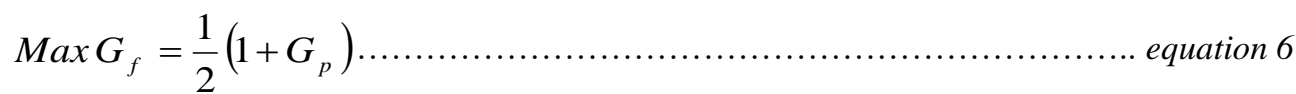

Where

$\mathrm{G}_{\mathrm{f}}=$ Fracture Gradient, psi 
$\mathrm{G}_{\mathrm{ob}}=$ Overburden Gradient psi/ft

$\mathrm{P}=$ pore pressure, $\mathrm{psi}$

If an overburden stress gradient $\left(\mathrm{G}_{\mathrm{ob}}\right)$ of $1 \mathrm{psi} / \mathrm{ft}$ is assumed;

$\operatorname{Min} G_{f}=\frac{1}{3}\left(1+2 G_{p}\right)$ equation 7

Matthews and Kelly's Method

Rock matrix is usually linked to the matrix stress and varies only with the degree of compaction, Matthews and Kelly build uped the following equation for calculating fracture gradients in sedimentary formations:

$\mathrm{G}_{\mathrm{f}}=\mathrm{G}_{\mathrm{p}}+\mathrm{K}_{\mathrm{i}}\left(\mathrm{G}_{\mathrm{ob}}-\mathrm{G}_{\mathrm{p}}\right)$ equation 8

Where,

$\mathrm{G}_{\mathrm{f}}=$ fracture gradient $(\mathrm{psi} / \mathrm{ft})$

$\mathrm{G}_{\mathrm{p}}=$ pore pressure gradient $(\mathrm{psi} / \mathrm{ft})$

$\mathrm{G}_{\mathrm{ob}}=$ overburden gradient $(\mathrm{psi} / \mathrm{ft}$ )

$\mathrm{K}_{\mathrm{i}}=$ matrix stress coefficient

$\mathrm{D}=$ depth of curiosity (ft)

Ben Eaton's Method

Ben Eaton extended the concepts offered by Matthews and Kelly to introduce Poisson's ratio into the expression for the fracture pressure gradient:

$$
G_{f}=\left[\left(G_{o b}-G_{p}\right)\left(\frac{v}{1-v}\right)\right]+G_{p}
$$
equation 9

Where,

$\mathrm{G}_{\mathrm{f}}=$ fracture gradient $(\mathrm{psi} / \mathrm{ft})$

$\mathrm{G}_{\mathrm{ob}}=$ overburden gradient $(\mathrm{psi} / \mathrm{ft})$

$\mathrm{G}_{\mathrm{p}}=$ pore pressure gradient (observed or predicted) $(\mathrm{psi} / \mathrm{ft})$

$v=$ Poisson's ratio

Eaton assumed that both overburden stress and Poisson's ratio varies with depth.

Poisson's ratio is a rock property that explains the behavior of rock stresses $\left(\sigma_{1}\right)$ in one direction (least principal stress) when pressure $\left(\sigma_{\mathrm{p}}\right)$ is applied in another direction (principal stress).

$\frac{\sigma_{1}}{\sigma_{p}}=\frac{v}{1-v}$ equation 10

Laboratory tests on unconsolidated rock have shown that generally

$$
\frac{\sigma_{1}}{\sigma_{p}}=\frac{1}{3}
$$

Substituting value of $\sigma_{1} / \sigma_{\mathrm{p}}$ into Equation 3.14 we have

$\frac{1}{3}=\frac{v}{1-v}$ equation 12

Solving for $\mathrm{v}$ we have

$V=0.25$

Results

Pore Pressure Forecast

The Ben Eaton's resistivity and Sonic time methods were selected for the purpose of forcasting pore pressures in this study. Two case studies will be conducted by using well data obtained from the Niger Delta area to demonstrate the models.

Eaton's Resistivity Method for Pore Pressure Forecast (Case Study 1)

The pore pressure model which adopted the resistivity parameters described by Eaton was deployed to evaluation pore pressure gradient and pore pressure estimation. Table 1 is the table of input data for the case study analysis conducted with this model; the 
plot of overburden pressure, pore pressure and normal formation pressure against depth (Figure 1), and Table 2 shows generated value of overburden pressure, pore pressure and normal formation for different depths within the formation region.

Table 1: Table of data resistivity method

\begin{tabular}{|c|c|}
\hline Input Data & Values \\
\hline TVD & 12000 \\
\hline $\mathrm{G}_{\mathrm{ob}}$ & 0.988 \\
\hline $\mathrm{G}_{\mathrm{pn}}$ & 0.468 \\
\hline Ra (d-units) & 1.1 \\
\hline Rn (d-units) & 1.5 \\
\hline
\end{tabular}

Table 2: Generated data of overburden, Pore and Normal Formation Pressures

\begin{tabular}{|l|l|l|l|}
\hline \hline TVD & \multicolumn{1}{|c|}{$\begin{array}{c}\text { Overburden Pressure } \\
\text { (psi) }\end{array}$} & $\begin{array}{c}\text { Formation Pore Pressure } \\
\text { (psi) }\end{array}$ & $\begin{array}{c}\text { Normal Formation Pressure } \\
\text { (psi) }\end{array}$ \\
\hline $\mathbf{5 0 0 0}$ & 4940 & 3148.012 & 2340 \\
\hline $\mathbf{5 0 1 0}$ & 4949.88 & 3154.30802 & 2344.68 \\
\hline $\mathbf{5 0 2 0}$ & 4959.76 & 3160.60405 & 2349.36 \\
\hline $\mathbf{5 0 3 0}$ & 4969.64 & 3166.90007 & 2354.04 \\
\hline $\mathbf{5 0 4 0}$ & 4979.52 & 3173.1961 & 2358.72 \\
\hline $\mathbf{5 0 5 0}$ & 4989.4 & 3179.49212 & 2363.4 \\
\hline $\mathbf{5 0 6 0}$ & 4999.28 & 3185.78814 & 2368.08 \\
\hline $\mathbf{5 0 7 0}$ & 5009.16 & 3192.08417 & 2372.76 \\
\hline $\mathbf{5 0 8 0}$ & 5019.04 & 3198.38019 & 2377.44 \\
\hline $\mathbf{5 0 9 0}$ & 5028.92 & 3204.67622 & 2382.12 \\
\hline $\mathbf{5 1 0 0}$ & 5038.8 & 3210.97224 & 2386.8 \\
\hline $\mathbf{5 1 1 0}$ & 5048.68 & 3217.26826 & 2391.48 \\
\hline $\mathbf{5 1 2 0}$ & 5058.56 & 3223.56429 & 2396.16 \\
\hline $\mathbf{5 1 3 0}$ & 5068.44 & 3229.86031 & 2400.84 \\
\hline $\mathbf{5 1 4 0}$ & 5078.32 & 3236.15634 & 2405.52 \\
\hline $\mathbf{5 1 5 0}$ & 5088.2 & 3242.45236 & 2410.2 \\
\hline $\mathbf{5 1 6 0}$ & 5098.08 & 3248.74838 & 2414.88 \\
\hline $\mathbf{5 1 7 0}$ & 5107.96 & 3255.04441 & 2419.56 \\
\hline $\mathbf{5 1 8 0}$ & 5117.84 & 3261.34043 & 2424.24 \\
\hline
\end{tabular}

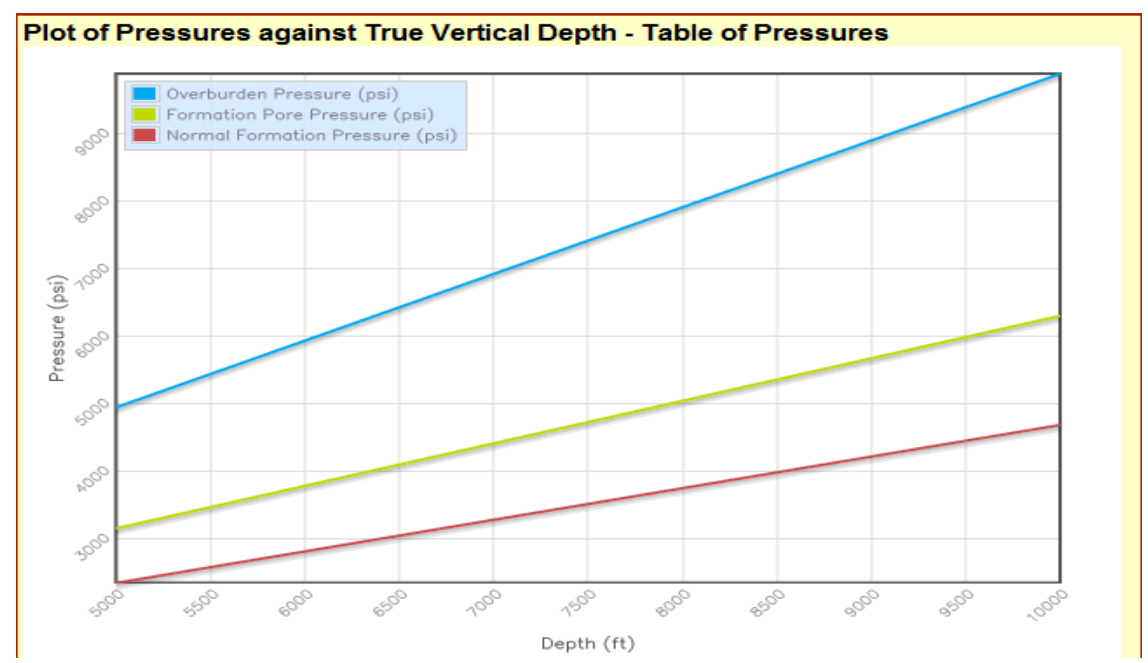

Figure 1: plot of overburden, pore and normal formation pressure against depth (Case study 1)

From Table 2, it can be inferred that the vertical depth chosen for analysis is $1200 \mathrm{ft}$ with overburden gradient of $0.988 \mathrm{psi} / \mathrm{ft}$ and normal pore pressure gradient of $0.468 \mathrm{psi} / \mathrm{ft}$ while $\mathrm{dc}_{\mathrm{n}}$ of $1.5 \mathrm{~d}$-units and $\mathrm{dc}_{\mathrm{a}}$ of $1.1 \mathrm{~d}$-units. By employing the Eaton's resistivity method, it was discovered that the pore pressure gradient for this formation was approximately $0.63 \mathrm{psi} / \mathrm{ft}$ and pore pressure at this depth of curiosity (12000ft) subsequently became approximately 7555psi.
For analysis in case study one in line with the pore pressure section of this model, the pore pressure gradient observed here was approximately $0.63 \mathrm{psi} / \mathrm{ft}$, which is an over pressured formation as the pore pressure exceeds the normal gradient of $0.465 \mathrm{psi} / \mathrm{ft}$. For this formation to be drilled safely, the gradient of the drilling-mud should not go below this $0.63 \mathrm{psi} / \mathrm{ft}$ or else it could result to a kick as well as a blowout due to influx of formation fluids into the wellbore. So a safe margin should be found above this observed pressure gradient of $0.63 \mathrm{psi} / \mathrm{ft}$. 
Eaton's Sonic Transit Time Method for Pore Pressure Forecast (Case Study 2)

The pore pressure method using sonic transit time parameters described by Eaton was deployed to ascertain pore pressure gradient and estimation. Table 3 is the table of input data for the case study analysis conducted with this model; the plot of overburden pressure, pore pressure and normal formation pressure against depth (Figure 2), and Table 4 shows generated value of overburden pressure, pore pressure and normal formation for different depths within the formation region.

Table 3: Table of data for Sonic Transit time method

\begin{tabular}{|c|c|}
\hline Input Data & Value \\
\hline TVD & 8000 \\
\hline $\mathrm{G}_{\mathrm{ob}}$ & 0.9375 \\
\hline $\mathrm{G}_{\mathrm{pn}}$ & 0.65 \\
\hline $\mathrm{t}_{\mathrm{a}}(\mu \mathrm{sec} / \mathrm{ft})$ & 130 \\
\hline $\mathrm{t}_{\mathrm{n}}(\mu \mathrm{sec} / \mathrm{ft})$ & 110 \\
\hline
\end{tabular}

Table 4: Generated data of overburden, pore and normal formation pressures

\begin{tabular}{|l|l|l|l|}
\hline TVD & \multicolumn{1}{|c|}{$\begin{array}{c}\text { Overburden Pressure } \\
\text { (psi) }\end{array}$} & \multicolumn{1}{|c|}{$\begin{array}{c}\text { Formation Pore Pressure } \\
\text { (psi) }\end{array}$} & \multicolumn{1}{|c|}{$\begin{array}{c}\text { Normal Formation Pressure } \\
\text { (psi) }\end{array}$} \\
\hline $\mathbf{5 0 0 0}$ & 4687.5 & 3256.236 & 2325 \\
\hline $\mathbf{5 0 1 0}$ & 4696.875 & 3262.74847 & 2329.65 \\
\hline $\mathbf{5 0 2 0}$ & 4706.25 & 3269.26094 & 2334.3 \\
\hline $\mathbf{5 0 3 0}$ & 4715.625 & 3275.77342 & 2338.95 \\
\hline $\mathbf{5 0 4 0}$ & 4725 & 3282.28589 & 2343.6 \\
\hline $\mathbf{5 0 5 0}$ & 4734.375 & 3288.79836 & 2348.25 \\
\hline $\mathbf{5 0 6 0}$ & 4743.75 & 3295.31083 & 2352.9 \\
\hline 5070 & 4753.125 & 3301.8233 & 2357.55 \\
\hline 5080 & 4762.5 & 3308.33578 & 2362.2 \\
\hline $\mathbf{5 0 9 0}$ & 4771.875 & 3314.84825 & 2366.85 \\
\hline 5100 & 4781.25 & 3321.36072 & 2371.5 \\
\hline 5110 & 4790.625 & 3327.87319 & 2376.15 \\
\hline 5120 & 4800 & 3334.38566 & 2380.8 \\
\hline 5130 & 4809.375 & 3340.89814 & 2385.45 \\
\hline 5140 & 4818.75 & 3347.41061 & 2390.1 \\
\hline 5150 & 4828.125 & 3353.92308 & 2394.75 \\
\hline 5160 & 4837.5 & 3360.43555 & 2399.4 \\
\hline 5170 & 4846.875 & 3366.94802 & 2404.05 \\
\hline 5180 & 4856.25 & 3373.4605 & 2408.7 \\
\hline
\end{tabular}

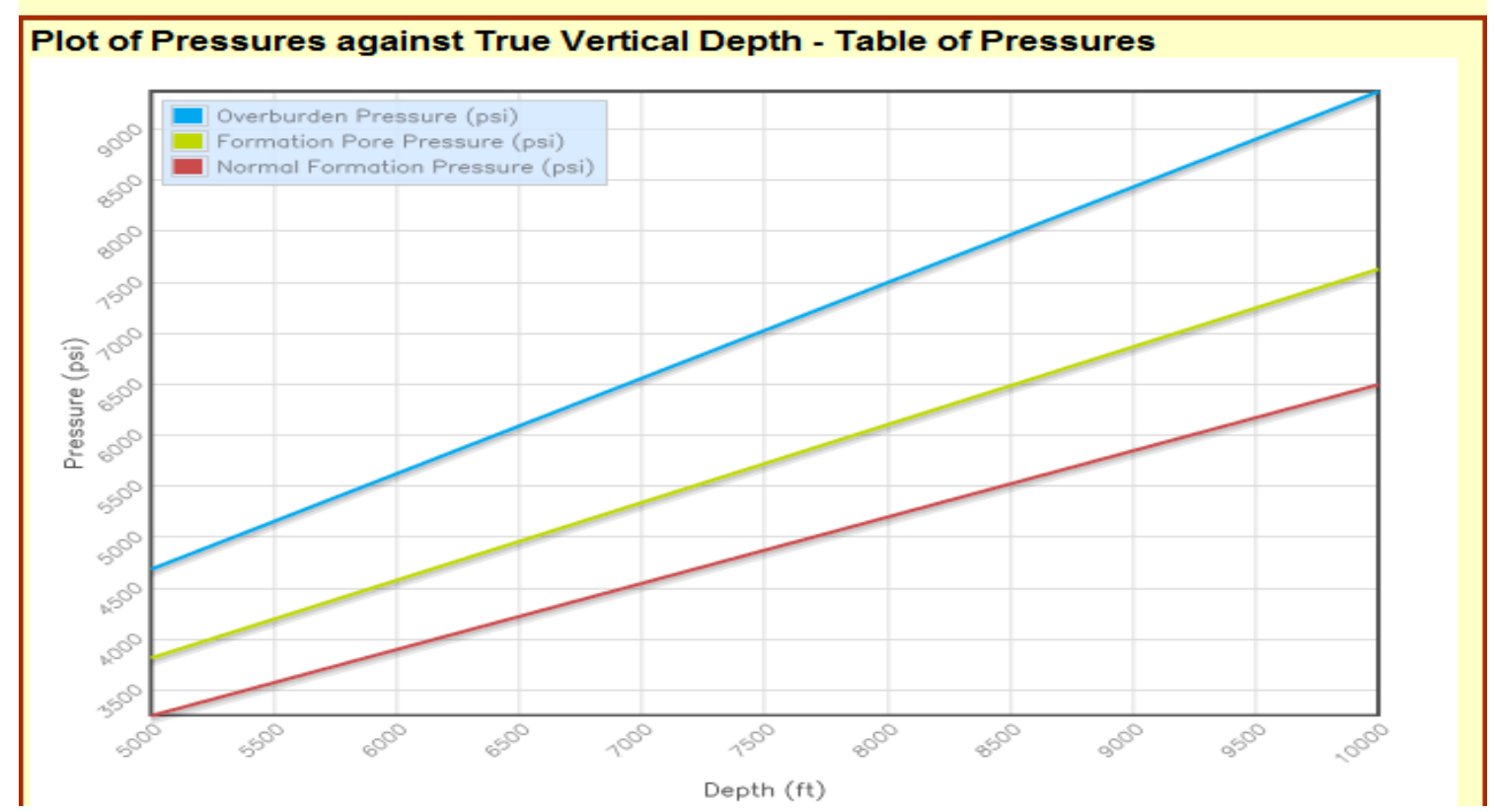

Figure 2: Plot of overburden, pore and normal formation pressure against depth (Case study 2) 
From Table 4, it can be inferred that the vertical depth chosen for analysis is $8000 \mathrm{ft}$ with overburden gradient of $0.9375 \mathrm{psi} / \mathrm{ft}$ and normal pore pressure gradient of $0.65 \mathrm{psi} / \mathrm{ft}$ while $t_{a}$ of $130 \mu \mathrm{sec} / \mathrm{ft}$ and $t_{n}$ of $110 \mu \mathrm{sec} / \mathrm{ft}$. By employing the Eaton's sonic transit time method , it was discovered that the pore pressure gradient for this formation was $0.763325 \mathrm{psi} / \mathrm{ft}$ and pore pressure at this depth of curiosity (12000ft) subsequently became approximately 6106psi.

For analysis in case study two conducted with the pore pressure section of this model, the pore pressure gradient observed here was approximately $0.763325 \mathrm{psi} / \mathrm{ft}$, which is an over pressured zone as the pore pressure exceeds the normal pore pressure gradient of $0.465 \mathrm{psi} / \mathrm{ft}$. For this formation to be drilled safely; the gradient of the drilling mud should not go below this $0.763325 \mathrm{psi} / \mathrm{ft}$ or else it could result to a kick as well as a blowout due to influx of formation fluids into the wellbore. So a safe margin should be found above this observed pressure gradient of $0.763325 \mathrm{psi} / \mathrm{ft}$. If the gradient of the drilling fluid falls below the value of the pressure gradient then it will be an under balanced drilling, while if it gets above the pressure gradient it will be an over balanced drilling but if on the other hand, it is equal to the observed gradient then it will result to a balanced drilling.

Fracture Pressure Forecast Strategies

This section of the study puts forward and discusses the results of fracture pressure by employing the methods as described by Eaton's, Kelly and Matthew and Hubbert and Willis. Results and discussion for each method are offered as follows.

Fracture Pressure Forecast Model Results

Table 5 indicates the input data with which the case study evaluation was conducted. The models used are Ben Eaton's, Hubbert and Willis and Mattew and Kelly's models.

Table 5: Table of Input Data for Fracture Pressure Forecast

\begin{tabular}{|c|c|c|c|c|c|}
\hline Data & Hubbert \& Willis & Ben Eaton & Ben Eaton & Ben Eaton & Ben Eaton \\
\hline Formation & $*$ & $\begin{array}{c}\text { Unconsolidated/ } \\
\text { Shale Kerogen-Rich }\end{array}$ & Dolomite & $\begin{array}{l}\text { Limestone Fine } \\
\text { Micrite }\end{array}$ & Very fine Sandstone \\
\hline TVD (ft) & 12000 & 12000 & 12000 & 12000 & 12000 \\
\hline $\mathrm{G}_{\mathrm{ob}}(\mathrm{psi} / \mathrm{ft})$ & 1 & 1 & 1 & 1 & 1 \\
\hline EMW (psi/ft) & 0.735 & 0.735 & 0.735 & 0.735 & 0.735 \\
\hline $\mathrm{G}_{\mathrm{pn}}(\mathrm{psi} / \mathrm{ft})$ & 0.465 & 0.465 & 0.465 & 0.465 & 0.465 \\
\hline $\mathrm{N}$ & $*$ & 0.25 & 0.21 & 0.28 & 0.04 \\
\hline
\end{tabular}

Table 6: Fracture Pressure Forecast Results

\begin{tabular}{|c|c|c|c|c|c|}
\hline Data & Hubbert \& Willis & Ben Eaton & Ben Eaton & Ben Eaton & Ben Eaton \\
\hline Formation & * & $\begin{array}{l}\text { Unconsolidated/ } \\
\text { Shale Kerogen-Rich }\end{array}$ & Dolomite & $\begin{array}{c}\text { Limestone Fine } \\
\text { Micrite }\end{array}$ & Sandstone very fine \\
\hline $\mathrm{G}_{\mathrm{p}}(\mathrm{psi} / \mathrm{ft})$ & 0.735 & 0.735 & 0.735 & 0.735 & 0.735 \\
\hline$\sigma(\mathrm{psi} / \mathrm{ft})$ & 0.265 & 0.265 & 0.265 & 0.265 & 0.265 \\
\hline $\operatorname{Min} G_{f}(p s i)$ & 0.823 & * & * & * & * \\
\hline $\operatorname{Max} G_{f}(p s i)$ & 0.868 & 0.823 & 0.805 & 0.838 & 0.746 \\
\hline $\mathrm{PP}(\mathrm{psi})$ & 8085 & 8085 & 8085 & 8085 & 8085 \\
\hline Min FP(psi) & 9057 & $*$ & $*$ & $*$ & $*$ \\
\hline Max FP(psi) & 9543 & 9057 & 8860 & 9219 & 8206 \\
\hline MS(psi) & 2915 & 2915 & 2915 & 2915 & 2915 \\
\hline
\end{tabular}

\section{Discussion of Fracture Pressure Forecast Results}

From analysis conducted different estimations for fracture pressure gradient was gotten depending on the formations involved when Ben Eaton Model was used. The value of this fracture gradient is of absolute importance to any driller to save cost and in order not to fracture any of this formation. As any gradient of drilling fluid above this fracture pressure estimation could cause an unnecessary loss of drilling fluid into the formation.

Absolute care should also be taken not to allow the gradient of the drilling fluid to fall below pore pressure gradient for this formation, as this could result to uncontrollable flow of the formation fluid out of the formation which could to a kick and then a blowout. 
From the above analysis, Ben Eaton model gave consideration to formation type, ranging from dolomite formation, Limestone Fine Micrite formation, Sandstone Very Fine, Shale Kerogen-Rich Formation/Unconsolidated Formations each of this formation had their own fracture gradient but Hubbert \&Willis Model didn't consider formation type.

In real sense Ben Eaton assumes that Overburden Gradient is a function of depth, but for this analysis a default overburden gradient of $1 \mathrm{psi} / \mathrm{ft}$ was used so as to compare value for fracture gradient and pressure as conditions for this analysis was meant to be the same.

At the end of the analysis it was observed that the fracture gradient pressure value was greatest for the Limestone Fine Micrite formation, followed by unconsolidated formations, followed dolomite formation and lastly by the very fine sandstone formation. But most of all it was seen that the value of fracture pressure gradient and fracture pressure gotten by Ben Eaton using unconsolidated formation was equal to that gotten by Hubbert \&Willis model for minimum fracture gradient and Minimum fracture pressure respectively, which therefore implies that the best models to be used for the forecast of fracture pressure values for unconsolidated formations should be Hubbert \&Willis Model and Ben Eaton Model using the value of Poisson's Ratio of 0.25.

The fracture gradient for very fine sandstone was found to be very close to its pore pressure, which means that absolute care need to be taken not to fracture this type of formation.

It was also seen that the formation pore pressure, fracture pressure, Matrix stress are all function of depth, in that their values was increasing as the depth of formation expandd assuming the their gradients was constant for this spectrum of formation depth.

The Matthew and Kelly's Model was not used in this evaluation as there was no clear value for matrix stress coefficient for unconsolidated formation, so this option was not deployed in this analysis, but is still present in this model, for those who wish to use this model to approximate fracture pressure the exact Matrix stress Coefficient for the reference point should be known.

\section{CONCLUSION}

Based on this study, the following conclusions are made; (1) a method for predicting pore pressure by employing the Ben Eaton's resistivity and sonic transit time model has been build uped; (2)The pore pressure predicted or approximated is depended on the overburden pressure gradient of the formation and the depth of curiosity; (3) A method for predicting the fracture pressure of a selected Niger Delta formation by employing three selected (Ben Eaton's, Hubbert and Willis and Mattew and Kelly) models; (4) The Eaton's model is dependent on the formation type and value of the overburden (assumed as 1psi/ft in this study) pressure gradient and pore pressure and also the depth of curiosity; (5) The Mattew and Kelly method could not be demonstrated because of the inability to obtain the matrix stress coefficient for the formation under study; (6) The
Ben Eaton's model is selected as the best Model for fracture pressure forecast for this study.

\section{REFERENCES}

[1] Bingham, M. G., Milchen, Inc. (1969). "What is balanced pressure drilling?". Fall Meeting of the Society of Petroleum Engineers of AIME, Denver, Colorado, USA, SPE 2541-MS.

[2] Bourgoyne A.T., Miliheim K.K and Chenevert M.E. (1984) “Applied Drilling Engineering” SPE Text books Series, 1984

[3] Bourgoyne, A.T. Jr, and Rocha, A.L. Jr. (1996): "A New, Simple Way to Estimate Fracture Pressure Gradient," SPEDC, September 1996, pp. 153 - 159.

[4] Bowers, G. L. (1995). Pore pressure estimation from velocity data: Accounting for overpressure mechanisms besides undercompaction. SPE Drilling and Completions. Dallas, USA.

[5] Carothers, J.W. (1948): "A Statistical Study of the Formation Factor Relationship," The Log Analyst, September - October 1948, pp. 14 - 20.

[6] Christman. S. (1973): "Offshore Fracture Gradients" J.Pet Tech (August 1973) 910-914.

[7] Eaton, B.A., (1969) Fracture Gradient Prediction and its Application in Oilfield Operations, Journal of Petroleum Technology, Vol. 10, pp. 1353-1360.

[8] Eaton, B.A (1969).: "Fracture Gradient Prediction and Its Application in Oilfield Operations," JPT, pp. 246

[9] Eaton, B.A., and Eaton, L.E. (1997): "Fracture Gradient Prediction for the New Generation," World Oil, p. 93.

[10] Eaton, B. A. (1972). "Graphical method to predicts geopressures worldwide". World Oil 7 (76): 100-104.

[11] Eaton, B.A.: "The Equation for Geopressure Prediction from Well Logs," paper SPE 5544 presented at the 1975 SPE Annual Technical Conference and Exhibition, Dallas,

TX,

September 28 - October 1.

[12] Hottman, C.E., and Johnson, R.K.: "Estimation of Formation Pressures from Log-derived Shale Properties," JPT, June 1965, p. 717

[13] Jorden J. R., and Shirley, O. J. (1966).: "Application of Drilling Performance data to Overpressure Detection". J. Petroleum Technology, 1387-1394.

[14] Macpherson, L. A. and Berry, L.N. (1972): "Prediction of Fracture Gradients" Log Analysis (October, 1972) 12.

[15] Mathews. W.R. and Kelly. J. (1967): "How to predict Formation Pressure and Fracture Gradient from Electric and Sonic logs" Oil and Gas J. (February 20, 1967)

[16] Matthews, W.R. (1972): "Here is How to Calculate Pore Pressure from Logs," Oil and Gas Journal.

[17] MI Drilling Fluids, Inc. (1999): "Plotting Pressures from Electric Logs," 1999.

[18] Mouchet J. P., and Mitchell, A. (1989):: "Abnormal Pressure while Drilling”. Manuals Techniques 2. Boussens, France, Elf Aquitaine Editions.

[19] Rehm, B.,and McCledon, R. (1971). "Measurement of Formation Pressure from Drilling data". Fall Meeting of the Society of Petroleum Engineers of AIME, New Orleans, Louisiana, USA. SPE 3601.

[20] Roegiers, J-C. (1987): "Rock Mechanics," Chapter 3 of Reservoir Stimulation, ed. Economides, M.J. and Nolte, K.G., Schlumberger Educational Services, 1987.

[21] Terzaghi, K., and Peck, M. (1968).: "Soil Mechanics in Engineering Practice". New York: John Wiley and Sons.

[22] Yoshida, C., Ikeda, S., \& Eaton, B. (1996).: "An investigative study of recent technologies used for prediction, detection, and evaluation of abnormal formation pressure in North and South America”. Kuala Lumpur, Malaysia. September 9-11. 